\title{
Socio Economic and Educational Development of People in Tribal Areas
}

\author{
Rasmi Ranjan Puhan ${ }^{1}$, Lakshmipriya Malla $^{2}$ \\ Asst. Professor (KISS), KIIT University, Bhubaneswar, Odisha \\ Asst. Professor (KISS), KIIT University, Bhubaneswar, Odisha
}

\begin{abstract}
The present study focuses on the actual socio economic condition of tribal people prevailing in Odisha. The study has been undertaken in the two tribal blocks of Kalahandi district such as Koksara and MadanpurRampur among the SHGs having bank linkage experience only. India's preoccupation with rural credit dates back to the pre-colonial period. Successive attempts by governments in the post-independent period failed in providing credit to the vulnerable and poor people in rural areas thereby leaving an estimated 38 per cent of household dependant to the informal sector lending. NABARD developed the SHG-Bank Linkage approach as the core strategy that could be used by the banking system in India to increase financial inclusion of the poor. Odisha is the only state in India that accommodates the largest number of STs and PTGs in her soil who is of course the matrix of poverty and leads an unprivileged and deprived life. This isolated group of our society has been perishing in the secluded, most backward, remote and inaccessible tribal region of the state in an ever impoverished mental, economic and physical conditions. To analyse the above subject matter three research questions were established and Focus of the questions ware: (i) Whether Micro-Financing has generated any impact to deal with the problem of isolation and secluded living style of tribal people; (ii) Whether MicroFinancing has created awareness in the minds of tribal people for development through any attitudinal transformation; (iii) Whether Micro-Financing has enhanced the tribal participation in development programmes to accrue increased benefits thereof. To study these questions same numbers of objectives are framed and which are the major thrust of this present study. Results of this study show that there is a clear empirical evidence of impact of SHGs in the lives of poor. The intervention has made significant change in the attitude of poor towards saving and on the other hand to mobilise a considerable quantum of credit with repeat support from formal financing institutions. The paper recommended several empirical steps to overcome these problems including provision of a better planning and implementation of the intervention with regular nurturing and support to the SHGs can result in better socio-economic outcome.
\end{abstract}

KeyWords: socio-economic, tribals, Micro-financing, PTGs, Kalahandi, Koksara, Madampur-Rampur, NABARD and SHG etc.

\section{INTRODUCTION}

A nation can be socially and economically strong only when none of its human population is without work and basic necessities. The so called chronically poor segment of our population is compelled to lead a life of gross impoverishment. Not only they lack a permanent income source but also fail in enjoying the most basic human freedom and rights, like food, clothing, shelter, health care, education, transportation, communication and political participation. These aspects of poverty are crucial for human development and socio economic development of poor people. India's preoccupation with rural credit dates back to the pre-colonial period. Successive attempts by governments in the post-independent period failed in providing credit to the vulnerable and poor people in rural areas thereby leaving an estimated 38 per cent of household dependant to the informal sector lending.

NABARD developed the SHG-Bank Linkage approach as the core strategy that could be used by the banking system in India to increase financial inclusion of the poor. Odisha is the only state in India that accommodates the largest number of STs and PTGs in her soil who is of course the matrix of poverty and leads an unprivileged and deprived life. This isolated group of our society has been perishing in the secluded, most backward, remote and inaccessible tribal region of the state in an ever impoverished mental, economic and physical conditions.

\footnotetext{
${ }^{1}$ Corresponding Author: rasmi.lakshmi@gmail.com
} 


\section{LITERATURE REVIEW}

There are two broad approaches characterize the microfinance sector in India i.e., the SHG bank linkage and MFI. The SBL is the larger model and unique in India but internationally MFI model has become increasingly favorite (Shah, Rao \& Shankar 2007). The SBL model is backed by government support and aimed at welfare and wellbeing of the society, where as the MFI models were managed by private donor agencies with a profit motive (Ghate 2007).They specialize in lending and recovering what they lend. They lend at a very high rate of interest and adopt coercive methods for loan recovery; evidences prove. As Ghate Calls, "Targeted towards profit, MFIs dump money on borrowers at any costs. They require security deposits as collateral. The most dubious practice of many MFIs is that, they charge interest on the entire remaining period as well, even if the borrowers return the loan early. This becomes a killing penalty. They lack transparency in their functioning. MFI lending is potentially explosive and is found to explode (Farmers' suicide in AP) when a large segment of borrowers is very poor and illiterate who lacks adequate information on the terms and conditions of loan (Scully 2004) MFIs are some times reported for adopting "abusive" collection practices which results in borrowing from money lenders to repay MFI loan (CGAP 2005). In extreme cases as poor borrowers usually abscond, migrate and commit suicide. Many research findings show that MFIs may benefit wealthier borrowers but it lowers welfare level of poor. MFIs are apprehended to repeat in India the situation of mushrooming private banks and rampant bank failure that the country witnessed during 1940s and 1950s (Stiglitz 1993). SBLP in India is the largest MF programme in the world initiated by NABARD in 1992 with the policy support of RBI (Sheokand 1998). To expand and spread the SBLP to promote savings and credit among unbankable poor in rural areas, RBI declared SHG lending as an additional segment under priority sector advances by banks. The SBLP has been sincerely implemented through SHPIs to bring the rural poor under the coverage of institutional credit thereby focusing on poverty alleviation and empowerment. The gender analysis of published data on SBLP reveals that $78 \%$ of SHGs in the country are women groups and the spread of SHG movement is skewed among Indian states (Rao and Dasgupta 1999). But the empirical study on SHGs and Bank branches in Indian southern states reveals that SHG linkage virtually reduces transaction costs, high loan recovery and zero default risk in comparison to direct lending (Puhazhendi 1995). For performance improvement of SBLP it is believed that members need to be familiar with the banking operation. In this regard sincere training of SHG members through NGOs are badly required on the conduct of meeting, maintenance of records, generation of awareness and bringing formal and financial literacy among poor SHG members (Puhazhendi 2000). In India there is the emergence of three distinct models of SHGs under the SBLP since 1992.

\section{RATIONAL OF THE STUDY}

The SHG - Bank Linkage programme has been one of the most rapidly expanding credit programmes in recent times and the model is being included in the development activities of many state agencies as a vehicle for socioeconomic development. NABARD observes that more than 400 women join the SHG movement in India every hour and that one NGO joins NABARD's microfinance programme every day. No study has been undertaken to study the outcome of such a rapidly expanding programme in view of eliminating poverty and bringing overall socio economic improvement of people living in the 5th schedule areas in the tribal dominated KBK region of Odisha as well as in the state and the country too. More over NGOs, banks and all the MF stake holders including SHG leaders, SHG members, members of SHG Hhs, will gain knowledge from the present study including every one having a little bit of interest in MF, poverty alleviation, rural development, tribal development, and women empowerment. No study has so far been undertaken to assess the impact of MF programme on the socio economic development of people in the two tribal blocks of the backward district of Kalahandi of Odisha covering the whole of the tribal regions of the district.

\subsection{Research questions}

The present study addressed with the following issues in hand:

1. Whether Micro-Financing has generated any impact to deal with the problem of isolation and secluded living style of tribal people;

2. Whether Micro-Financing has created awareness in the minds of tribal people for development through any attitudinal transformation towords education;

3. Whether Micro-Financing has enhanced the tribal participation in development programmes to accrue increased benefits thereof. 


\subsection{Objectives of the Study}

The present study focuses on the following objectives:

$>$ To assess the impact of MF on economic (employment, income, expenditure, savings, borrowing and asset possession) and social (Food, education, health and gender) development of people in tribal areas.

To examine the extent of women's participation in the decision making in family and society indicating their empowerment after their involvement in SHG activities.

To study the participation level of tribal's in different developmental activities to increase their benefits.

\subsection{Methodology of the study}

Descriptive survey method used in the study as the investigators tried to get information about more than one variable and assigned numerical value to those variables also with better understanding of perceptions of stakeholders (Hittleman and Simon, 1997). Through this method information about conditions, situations and events that occur in the present can be obtained (UNESCO, 2005). The study is essentially a descriptive one. It aims at describing and exploring the various changes with respect to a set of socio economic as well as their educational parameter to assess the level of development between the STs and non STs after joining SHG under MF programme.

\subsection{Sample of the study}

The study has been undertaken in the two tribal blocks of Kalahandi district such as Koksara and Madanpur-Rampur among the SHGs having bank linkage experience only.

\subsection{Tools of the study}

Taking data mainly from Questionnaire for the Sample Respondents and Odisha's Economic Surveys and the Census of India for various years, District statistical hand book, District at a glance, District Gazetteer and information collected from offices like District collector, Panchayats, Banks, etc. Besides this, secondary data have also been collected from monographic, research reports, research papers, journals, books and from internet, the scenario of Socio-economic condition of tribal people in Odisha over the years is seen and compared before and after implementation of policies.

\section{DISCUSSION}

Overall socio Economic Development

\begin{tabular}{|l|l|l|l|}
\hline \multirow{2}{*}{ Hh Classification } & Level of Improvement & Not at all \\
\cline { 2 - 4 } & Significant & Moderate & \\
\hline Category & $65(19)$ & $167(52.5)$ & $96(29.5)$ \\
\hline ST & $41(33)$ & $58(46.4)$ & $22(17.6)$ \\
\hline Non ST & $17(16.6)$ & $40(39.6)$ & $44(43.8)$ \\
\hline Age of SHG (in Years) & $32(21.5)$ & $85(54)$ & $40(24.5)$ \\
\hline Up to 3 & $30(26.4)$ & $58(51.8)$ & $24(21.8)$ \\
\hline $4-6$ & $27(34)$ & $42(53)$ & $10(13)$ \\
\hline $7-9$ & \multicolumn{5}{|l|}{} \\
\hline Above 9 & $16(10.4)$ & $74(48)$ & $64(41.6)$ \\
\hline No. of Bank Linkages & $56(28.7)$ & $95(48.7)$ & $44(22.6)$ \\
\hline Up to 2 & $34(34)$ & $56(56)$ & $10(10)$ \\
\hline $3-4$ & $106(23.1)$ & $225(50.6)$ & $118(26.3)$ \\
\hline $5 \&$ above &
\end{tabular}

Source: Self Compiled (Figures in the parenthesis indicate \%)

The above table shows that there is a problem of socio economic backwardness of people in tribal areas rests on the low level of their socio economic development. MF as a policy measure through SHGs has displayed improving the SED of people more significantly and sustainably than any other welfare programme implemented in the tribal areas so far. The essence of SHG programme of NABARD is to bring the ever excluded poor people into the fold of formal banking networks through SHG. In fact SHG is a vehicle through which the sublime goal of NABARD's MF 


\section{American Research Journal of Humanities and Social Sciences, Volume 1, Issue1, Feb-2015 ISSN 2378-7031}

programme designed for the socio economic upliftment of the poor people is expected to be realized. In this context the present study finds a positive and a very high degree of correlation between the SED of people and the length of their SHG experience in one hand, and SED and number of bank linkage availed by SHG members on the other hand. As such the researcher finds enough strength in the NABARD's innovative programme of SBLP in the reduction of extreme poverty and underdevelopment among the backward people residing in the tribal areas of Kalahandi district. If Implemented in the true sense of the term with the missionary zeal by the various stake holders the programme is expected to bring desired outcome in the alleviation of poverty in the areas similar to the present one beyond the district beyond the state and even beyond the country.

Improvement Participation in Development Programmes (EDUCATION Etc.)

\begin{tabular}{|l|l|l|l|}
\hline Hh Classification & Significant & Moderate & Not at all \\
\hline ST & $112(35)$ & $168(52)$ & $44(13)$ \\
\hline Non ST & $42(34)$ & $62(50)$ & $21(16)$ \\
\hline Age of SHG (in Years) & \multicolumn{4}{|l|}{} \\
\hline Up to 3 & 28 & 58 & 5 \\
\hline $4-6$ & 55 & 79 & 23 \\
\hline $7-9$ & 44 & 52 & 16 \\
\hline Above 9 & 17 & 41 & 21 \\
\hline No. of Bank Linkages & \multicolumn{3}{|l|}{} \\
\hline Up to 2 & 53 & 95 & 6 \\
\hline 3-4 & 69 & 90 & 36 \\
\hline $5 \&$ above & 32 & 45 & 23 \\
\hline Overall & $154(34)$ & $230(51)$ & $65(15)$ \\
\hline
\end{tabular}

Source: Self Compiled Figures in the paranthesis indicate\%

Among the SHG members 85 percent is agreed to have better participation in various development programmes. Overall 34 percent of respondents agreed that their participation level in government led development programmes has significantly improved in the post SHG situation where as 51 percent witnessed moderate improvement in this regard. The percentage of member having no improvement at all is 15 even after a long stay in SHGs. The average score of tribal Hhs has been more than the non tribals which indicates improved participation by the former than the later. Members from the older SHGs above 9 years of age have scored the lowest average score than the younger SHGHhs . This implies that at a later stage of SHG development people become more capable and self relient and concentrate on their own activities without depending much on government programmes. Further it is observed that there is an inverse relationship between the number of bank loan and the level of participation of people in welfare programme. Thus it can be undoubtedly concluded that the MF programme has improved the level of participation of people in development programme but longerSHG experience and more number of bank loan are likely to reduce in long run.

Improvement in initiating social actions

\begin{tabular}{|l|l|l|l|}
\hline \multicolumn{1}{|c|}{ Hh Classification } & Significant & Moderate & Not at all \\
\hline ST & 82 & 209 & 33 \\
\hline Non ST & 39 & 70 & 16 \\
\hline Age of SHG (in Years) & 30 & 58 & 13 \\
\hline Up to 3 & 48 & 95 & 14 \\
\hline $4-6$ & 29 & 64 & 19 \\
\hline $7-9$ & 14 & 62 & 3 \\
\hline Above 9 & \multicolumn{3}{l|}{} \\
\hline No. of Bank Linkages & 26 & 111 & 17 \\
\hline Up to 2 & 48 & 123 & 24 \\
\hline 3-4 & 47 & 45 & 8 \\
\hline 5 \& above & $121(27)$ & $279(62)$ & $49(11)$ \\
\hline Overall & \multicolumn{2}{|l|}{} \\
\hline
\end{tabular}

Source: Self Compiled Figures in the parenthesis indicate \% 


\section{American Research Journal of Humanities and Social Sciences, Volume 1, Issue1, Feb-2015}

ISSN 2378-7031

Significant improvement and 62 percent (ST=66\% \& Non ST $=56 \%$ ) have attained moderate improvement in initiating social action in the post MF period. However 11 percent of members opine no improvement in this regards. The level of improvement has been more for the non STs with. The level of improvement of people in taking up social action across the age of SHGs shows no trend. How ever the numbers of bank loan availed by SHG Hhs has positive relationship with the social action taken up by them. Thus women in SHGs have joined their hands and are working together to address important social issues that affect peoples' lives in a most adverse manner in tribal communities.

Improvement in the Level of General Wellbeing of Shg Hhs

\begin{tabular}{|l|l|l|l|}
\hline Hh Classification & Significant & Moderate & Not at all \\
\hline ST & $88(29)$ & $161(50)$ & $75(21)$ \\
\hline Non ST & $55(46)$ & $27(22)$ & $43(32)$ \\
\hline Age of SHG (in Years) & 10 & 39 & 52 \\
\hline Up to 3 & 60 & 47 & 50 \\
\hline $4-6$ & 38 & 67 & 7 \\
\hline $7-9$ & 35 & 35 & 9 \\
\hline Above 9 & 15 & 22 & 117 \\
\hline No. of Bank Linkages & 75 & 34 & 86 \\
\hline Up to 2 & 53 & 32 & 15 \\
\hline 3-4 & $143(32)$ & $188(42)$ & $118(26)$ \\
\hline 5 \& above & \multicolumn{3}{l|}{} \\
\hline Overall &
\end{tabular}

Source: Self Compiled Figures in the paranthesis indicate \%

The Percentage of respondents who feel significant improvement in their family wellbeing has been 32 out of which the percentage of STs (29) is less than the non STs (46).Moderate improvement in the well being of family is felt by 50 percent and 22 percent of tribal and non tribal Hhs respectively. The higher average score of non tribal Hhs reflects that the non tribals have been relatively better performer than the tribal Hhs due to MF programme. Across the SHG age the level of improvement is found increasing with the length of SHG membership. Hhs with longer SHG experience have attained grater level of family wellbeing than the Hhs with lower SHG experience. This is so because the average score of members inSHGs over 9 years of age is found to be more than that of the Hhs within 3 years of SHG experience. The number of bank linkage has also influenced the improvement of general wellbeing of people in a positive manner. This implies strong and positive outcome of SHG programme in initiating socio economic improvement among people in tribal areas.

\subsection{Major findings}

Results of this study show that there is a clear empirical evidence of impact of SHGs in the lives of poor.

The intervention has made significant change in the attitude of poor towards saving and on the other hand to mobilise a considerable quantum of credit with repeat support from formal financing institutions.

$>$ Most of the people during the pre SHG period were found in food gathering stage. They used to get food materials from agriculture mainly from shifting cultivation, collection of wild forest products, collection of NTFP for sale, rearing of animals and working as labourers and migrated workers.

$>$ Before SHG it was informed by the respondents that around 80 percent of Hhs constituting 81 percent of tribal and 77 percent of non tribal had no food available of for whole of a year in spite of their strong efforts to meet the Hhs food deficit situation. But the scenario has completely changed in the post SHG situation where 76 percent enjoy food availability which comprises 75 percent ST and 80 percent of non ST Hhs respectively.

$>$ The impact of MF on education has been studied separately on children, women and men in SHGHhs on the basis of their category, SHG age and number of bank linkages in the post SHG situations.

> The impact of MF programme on the improvement in the health conditions of people on the parameters like changes in the incidence of illness, methods of treatment of diseases, level of health awareness and the maintenance of cleanliness and hygiene among SHGHhs between the pre and post SHG period.

$>$ It has helped people fulfil minimum basic requirements of human life in terms of food, cloth, shelter, education, health etc for a decent living. 
It has helped to improve the socio-economic significance of women through their participation in different IGAs and non IGAs either individually or collectively or both to attain a higher level of women's empowerment.

$>$ It has helped to improve the awareness level of people in general and women in particular in various aspects of their lives to bring socio economic transformation.

$>$ It has helped people to improve their access to development programmes and institutions.

$>$ It has helped people to improve their socio economic conditions through progressive change in their attitude and actions.

\section{SUGGESTIONS}

The paper recommended several empirical steps to overcome these problems including provision of a better planning and implementation of the intervention with regular nurturing and support to the SHGs can result in better socio-economic outcome.

$>$ In several cases, bankers show unenthusiastic attitude in promoting SHGs. Occasionally, they point out reasons like shortage of staff, time, etc. just to avoid dealing with SHG promotion. Importance in terms of rigorous training for capacity building and to change their attitude should be thrust upon bankers for strengthening the SHGs movement.

$>$ In several cases, bankers show unenthusiastic attitude in promoting SHGs. Occasionally, they point out reasons like shortage of staff, time, etc. just to avoid dealing with SHG promotion. Importance in terms of rigorous training for capacity building and to change their attitude should be thrust upon bankers for strengthening the SHGs movement.

$>$ The MF programmes through SHG reach the poor (non STs) people but has not served the needs of the extremely poor (STs).The relatively better off Hhs utilise the MF services more extensively than the poor Hhs. So there must be different choices of intervention for the different segment of population. A uniform strategy is unlikely to succeed. Banks must design innovative micro credit products to suit the needs of different segments of society.

$>$ Women in tribal areas prefer to remain as wage earners or strive on collecting NTFP for Hhs sustenance. These women want a loan and if not given (due to any reason) get impatient and quit the group and join in some other groups. The Chinese proverb says "It is better to teach a person to fish than to provide him fish every day". While it is important to teach how to fish, most of the women particularly tribal women can not even reach the river. In this environment the strategy must be framed to increase the earning capabilities of people by through skill upgradation creating employment opportunities in tribal areas.

The target oriented approach of SHPIs has up scaled the formation of SHGs in tribal areas. Apart from expansion, all out efforts should be concentrated on nurturing and strengthening the existing groups. Greater thrust must be given to members on human resource development through orientation training and exposure visits.

Training programmes have been limited to the leaders only in most of the groups. Dissemination of information at the members' level has been adversely affected. Therefore, the urgent need of providing orientation as well as skill based training to these group members is a serious need of the hour.

\section{CONCLUSION}

Positive changes have taken place in the attitude of the beneficiaries and their communities at large. Self-perception which was very low before the introduction of MF programme among people in the backward areas is high now because of the change in attitude and social outlook. SHGs have provided a forum for women to express their concerns and articulate their aspirations for change (power within and power with) and enabled them to see and know what is happening outside their isolated abode. In spite of several drawbacks, members in general unanimously expressed the view that some improvement in their living style had taken place as a result of their participation in MF programme.

\section{REFERENCES}

[1] CGAP (2004) "Interest Rate Ceilings and MF: The Story so far", Occasional Paper, Washington.

[2] Ghate, P (2007) “Consumer Protection in Indian MF: Lesson from Andhra Pradesh and the Microfinance Bill” Economic and Political Weekly, Vol. XLII, No. 13. 
[3] Hittleman, D. R. and Simon, A. J. (1997), Interpreting Educational Research: An Introduction for Consumers of Research, Prentice-Hall, Inc. New Jersey.

[4] Puhazhendi, V (1995) "Transacting Cosy of Lending to the Poor- NGOs and SHGs of the Poor as intermediaries for Banks in India", The Foundation Development Cooperation, Bulletin,No. 19, IRMA, ANAND.

[5] Puhazhendi, V (2000) "Evaluation study of SHG in Tamilnadu” NABARD, Mumbai.

[6] Rao, K. D and Dasgupta, R (1999) “A Study of SHG and Linkage Programme”, NIMB, Pune.

[7] Shah, M R Rao and PS Vijay Shankar (2007) "rural Credit in 20th Century India, An Overview of History and Perspectives". Hermes and Lensink.

[8] Scully, N (2004) "Micro Credit, No Panacea For Poor Women", Global Development Research Centre, Washington,http://www.grdc.org/icm/wind/micr.html.

[9] Stiglitz, J (1993) “ The role of the state in financial market”, World Bank Economic Review.

[10] Sheokand, S M (1998) "Reorienting Banking With the Poor- The SHG- The Bank Linkage in MF: A Challenge for Indian Banks", BIRD, Lucknow.

[11] UNESCO (2005), Quantitative Research Methods in Educational Planning, UNESCO International Institute for Educational Planning, Paris, France.

\section{AUTHORS' BIOGRAPHY}

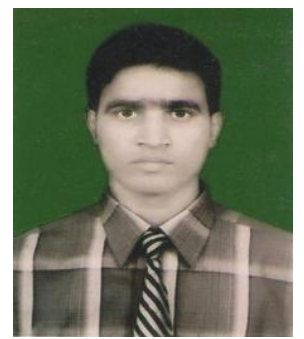

Rasmi Ranjan Puhan is working as an Assistant Professor in the Department of education, KIIT University (KISS), Bhubaneswar, Odisha, India. He has obtained Post Graduation in Education, NET, B.Ed and submitted his Ph.D in Tribal education In Utkal University,Odisha. He has guided 2 M.A degrees. He has published Near about 35 articles in several papers in National and International Journals.

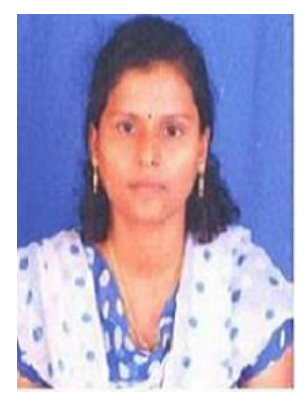

Lakshmipriya Malla is working as an Assistant Professor in the Department of education, KIIT University (KISS), Bhubaneswar, Odisha, India. She has obtained Post Graduation in Education and English, M. Phil, NET, B.Ed and submitted his Ph.D in Teacher Burnout In Utkal University,Odisha. She has guided 2 M.A degrees. She has published near about 30 articles in several papers in National and International Journals. 